\title{
Body-mind unity and the spiritual dimension of Modern Postural Yoga
}

\section{Introduction}

This article is concerned with the connection between body and mind that the practice of yoga is expected to develop and it aims specifically to examine the relationship between this body-mind connection and the spiritual dimension of yoga practice. The article particularly focuses on contemporary forms of yoga. Since these forms feature predominantly the practice of yoga postures or asanas, I will employ throughout the term Modern Postural Yoga (hereafter MPY), which was coined by historian Elizabeth De Michelis (2004). This article draws on a number of scholarly sources as well as my own involvement as a practitioner and teacher of Iyengar Yoga in London.

\section{Body-mind spirituality in Modern Postural Yoga}

According to De Michelis, yoga underwent such a radical refashioning from the mid-1880s onwards, that the scholar draws a clear distinction between pre-modern forms of the discipline and what she terms Modern Yoga. MPY is one aspect of Modern Yoga and, as the name suggests, it primarily features the practice of yoga poses. Within an MPY context the practice of yoga postures has acquired unprecedented attention and has reached a high degree of sophistication. More importantly, the meditational and spiritual aspects with which the discipline was originally identified are now regarded as a byproduct of asana practice. Following a close examination of Iyengar Yoga, 'arguably the most influential school of Postural Yoga to date' (De Michelis 2004: 4), De Michelis draws attention to the founder's emphasis on presenting the practice of yoga poses as a form of meditational activity in and of itself, which can, furthermore, have a spiritual dimension. In The Tree of Yoga, Iyengar puts forward a developmental model, according to which 'the mastery of asanas and pranayama [breathing exercises] leads automatically towards concentration and meditation' (1988: 8, as quoted in De Michelis 2004: 242). Equally, 
samadhi, the ultimate state of liberation that can be achieved through yoga, is considered by Iyengar to be an 'effect' of asana practice (1988: 8, as quoted in De Michelis 2004: 242).

It becomes clear therefore, that within an MPY context, yoga postures are not simply regarded as one component of the practice, but the very means by which spiritual development and personal growth can be achieved. Furthermore, the execution, performance, and teaching of these postures exhibit a high degree of 'orthoperformance'. In other words, MPY sessions do not deal with the teaching and/or explanation of philosophical, religious or metaphysical ideas, but with the practice of the poses and their anatomical details; the angle at which a knee should be bent, the direction in which a muscle should rotate, the number of foam pads on which one should sit in order to enable the optimal position of the spine. Furthermore, the teacher's/practitioner's ability to convincingly demonstrate and impart this kind of technical knowledge is often regarded as a proof of one's in-depth understanding of the overall practice, ethical integrity, and psychophysical integration. One's skeleto-muscular understanding of the poses constitutes, therefore, a form of physical capital with cultural as well as spiritual connotations. ${ }^{1}$

The interconnection between technical expertise in the poses, a meditative state of mind, and a potential for spiritual development not only underlies the promotion and practice of MPY, but in some cases has been taken for granted by scholars. For example, scholar of religion Paul Heelas refers to yoga and other psychophysical disciplines as 'body-mind spiritualities' and 'holistic spiritualities', which should be furthermore 'distinguished from spiritualities associated with a God of transcendent theism' (2008: 27). Heelas specifically claims that 'granted the importance of holism. . .spirituality ultimately belongs to - more accurately, should be enabled to flow through - the mind-body nexus' (Heelas 2008: 27, emphasis in original). Although Heelas does not draw any distinction among the various practices he places under the 'holistic spiritualities' umbrella, his position bears resemblance to Iyengar's formulation; engagement with the body, through yoga or any other psychophysical discipline, is seen as having cognitive, mental, and emotional implications, and potentially a spiritual character. ${ }^{2}$

1 For a discussion of Pierre Bourdieau's notion of physical capital and its transformation into economic, cultural and/or social capital see Shilling 1991: 654 .

2 The tendency to equate the practice of yoga with body-mind unity could also be seen as a residual characteristic of an orientalist approach. Drawing on the work of Edward Said, David Brown and Aspasia Leledaki assert that 'body-mind unity and 
Nevertheless, there are other voices which sound more suspicious of such an equation. Joseph Alter, for instance, points out that 'the advocacy of yoga as an embodied philosophy in fact exhibits a degree of anxiety and ambivalence about the inherent unity of mind, body, spirit' (2008: 37). The issue is further complicated by the fact that we are dealing with words and notions which are slippery and could be understood and defined in a number of ways. What do the words 'spiritual', 'body', 'mind' actually mean? Do we understand body and mind from the perspective of one of the Western philosophical traditions, or through the lens of one of the schools of Indian thought? Do we approach the concept of the 'spiritual' in relation to a particular religion, whether Eastern or Western, or do we adopt a New Age perspective? Although these words are at the very centre of yoga practice, yoga exponents do very little to clarify them. In fact, this lack of clarity is a chief factor in yoga's popularity with and appeal to people of different ages, genders, ethnicities and religions. According to De Michelis, the architects of modern forms of yoga consciously distanced the discipline from any specific religious dogma and embraced or coined terms that could be interpreted in a number of ways by a number of people. ${ }^{3}$ This strategy proved very successful with twentieth-century practitioners and indeed, the absence of a definitive spiritual or religious agenda is not perceived as a negative, but rather as a positive characteristic of the practice. Silvia Prescott, a senior Iyengar Yoga teacher, for example, argues that if the teacher gives " spiritual teaching" people can delude themselves and almost hypnotize themselves into thinking they're having a spiritual experience. Whereas if [the teacher] leaves it undefined they'll find something real for themselves - they won't put it in terms somebody else has given them' (Maimaris 2006: 28). Prescott's opinion reveals two important notions that underlie the practice of MPY. First of all, the practice favours personal experience over dogmatic tenets, and second it demonstrates a belief in the person's ability to attain spirituality by herself, that is without any form of spiritual guidance and outside or independently of a particular group and environment. MPY, therefore, is vehemently presented as a form of spiritual practice, but spirituality is left undefined with equal fervour.

Keeping in mind the importance attached to the belief that the practice of yoga poses can cultivate the integration of body and mind which can then

self-reflexivity [are] assumed to be essentially embedded in the indigenous embodied practices and philosophies of the East' (2010: 129).

Perhaps the best example of hazy terms that feature in the lingua franca of contemporary yoga is 'self-realisation', 'the marvelous ambiguities' of which, as De Michelis states, 'allow it to become all things to all people' (2004: 223). 
translate into or lead towards spiritual growth, this article aims to raise the following questions. Does MPY promote the integration of body and mind? How can such integration be framed and analysed? And (how) can such integration acquire a spiritual character? In an attempt to approach these questions, I will examine MPY from two different perspectives. I will first employ a phenomenological lens in order to offer an account of what goes on, what happens to the practitioner. I will then adopt a discursive perspective informed by cultural materialism in order to unpick some of the ideologies that underlie the pedagogy and practice of yoga postures. I will not examine yoga through the perspective of Indian metaphysical thought, although such an approach would have its merits. The reason for which such an approach will not be employed is that I consider MPY to be a modern phenomenon. Although yoga, and indeed MPY may have been influenced by Indian or Hindu notions about the body, the mind, and spiritual transcendence, yoga is primarily practised today within capitalist, western(ised), (post)modern cultural and social networks. As such, even if Indian metaphysical thought underlies MPY, the practice, dissemination as well as the social functions of yoga are determined by notions of health and fitness, rather than religious expression, and operate within the economic landscape of late capitalism. ${ }^{4}$ For this reason, I will examine the body-mind question through distinctively Western disciplines.

In a nutshell, phenomenology has foregrounded the role of the body in the production of meaning, as well as the importance of the body as a locus of experience; our embodiment is not some kind of acoutrement to an omnipotent mind; it is the absolute prerequisite for being in and interacting with the world. The philosopher Maurice Merleau-Ponty has argued for the 'lived body', the body that is present and involved in the constitution of meaning, one's sense of self and identity. As the social scientists Simon J. Williams and Gillian Bendelow argue, phenomenology, and particularly Merleau-Ponty's work, comprises an alternative to the Cartesian body-mind dualism that has underpinned much of Western thought and 'provides us with the philosophical foundation for a truly non-dualist ontology of the body' (Williams \& Bendelow 1998: 51). As such, phenomenology can offer an appropriate framework for examining the relationship between body and mind which the practice of MPY seeks to cultivate. 
On the other hand, cultural materialism can offer a more discursive perspective and thus shed light on the ideologies that underpin the practice of MPY. Cultural materialism could be described as a refined version of Marxism and its application in cultural studies was developed by the literary scholar Raymond Williams (1921-92). Theatre scholar Simon Murray explains that

...the paradigm of cultural materialism insists that. . .any art form is of the world and not simply in it. Thus, a crucial dimension to understanding and explaining any artistic practice is to place it, to see it, to hear it and to "unpack" it in such a way as to reveal social and cultural imprints on its form and content. (Murray \& Keefe 2007: 27, emphasis in original.)

Although cultural materialism has been predominantly employed in scholarship on art and theatre, it can comprise an important tool in an attempt to foreground the socio-political ideologies that underpin the ways in which MPY endeavours to train body and mind.

Finally, it should be noted that my decision to approach yoga through the aforementioned perspectives has been informed by similar distinctions I have encountered in the literature on the body. For example, the philosopher Elizabeth Grosz argues that schools of philosophy and approaches towards the subject and the body could be divided into two categories: 'the inside out' category which, according to Grosz, 'focuses on the way in which the subject's corporeal exterior is psychically represented and lived by the subject' (Grosz 1994: xii), and the 'the outside in' approach which 'emphasizes. . .the ways in which the social inscriptions of the body produce the effects of depth' (1994: xiii). As such, Grosz indicates that 'psychoanalysis and phenomenology focus on the body as it is experienced, rendered meaningful, enmeshed in systems of significations', whereas 'Nietzsche, Foucault, Deleuze, Lingis and others. . . focus on the body as a social object, as a text to be marked, traced, written upon by various regimes of institutional (discursive and nondiscursive) power. . . (Grosz 1994: 116). Based on the aforementioned distinctions, therefore, I will examine MPY as a psychophysical experience on the one hand and as a mode of social inscription on the other. However, I should also indicate that an examination of MPY through these lenses will lead to contradictory positions, which however do not exclude one another, but rather co-exist and weave the very texture of the practice. 


\section{Yoga as psychophysical experience}

The few accounts that examine yoga as an experience are firmly rooted in a phenomenological framework and draw from the work of eminent phenomenologists. I will first concentrate on an article by Klas Nevrin, which examines MPY practices in relation to the practitioner's 'lived experience' (2008: 123). Nevrin particularly suggests that the practice of MPY allows the practitioner to focus on the body, since the practice of yoga poses does not carry an outwards oriented intention; the execution of a movement aims at the execution of this particular movement and nothing more. In this manner, one is able to become more aware of physical as well as habitual patterns and also to develop a 'heightened attention to feeling movement' (Nevrin 2008: 125). Such an engagement, Nevrin supports 'will typically alter the practitioner's sense of self and body' and he further contends that 'these changes' might be experienced by novices as 'highly positive' (Nevrin 2008: 125). An alteration in the mode of one's attention has also an emotional dimension, although, as Nevrin argues, emotion is never addressed in an MPY context (Nevrin 2008: 128). Nevertheless, Nevrin identifies 'in bodily actions. . .structures of experience that invite for $[s i c]$ affective and imaginative elaboration in certain directions' (Nevrin 2008: 129). Furthermore, the manner in which MPY practices direct attention and pay attention to the body, can be for Nevrin 'existentially empower[ing]', since they can 'counteract detached and inflexible modes of experiencing' (Nevrin 2008: 130). Nevrin's account points at important dimensions of the practice of yoga. First of all, Nevrin seems to suggest that yoga allows the phenomenologist's 'absent body' to become present. ${ }^{5}$ By directing attention to the body, the body is no longer the silent and quiet 'from' that enables one's engagement in and with the world. The body is rather thematised and thus physical and kinaesthetic awareness is foregrounded. Second, such awareness is inextricably connected to affective, mental and behavioural aspects of the individual and Nevrin explicitly mentions the possibility of empowerment. A better understanding of what Nevrin means by empowerment can be gained by looking at the concept of appropriation. practitioner Drew Leder (1990). According to Leder, the body is the 'from', the starting point of our engagement with the world, and as a result our enmeshment in the world renders the body obsolete. In normal quotidian activity, therefore, the body recedes in our awareness, precisely because our attention is directed from the body to something else. 
The phenomenologist Eliot Deutsch regards the body as an 'achievement concept' and suggests that 'persons have bodies to the degree to which they appropriate the physical conditions of their individuality and become integrated...psychophysical beings' (1993: 5). Body-appropriation, therefore, comprises 'the bringing of the physical conditions of one's individual being into the matrix of one's personal identity and self-image' (Deutsch 1993: 5). Deutsch understands body appropriation in a developmental sense and he specifically cites the physical growth and changes that mark childhood. In this respect, body appropriation is not seen as a final product, but a constant process. In view of Deutsch's argument, one could support the idea that yoga is one such technique that can enable the individual to gain a better understanding and/or more heightened experience of her physicality. Furthermore, the heightened and developed physical awareness can result in emotional and mental insight. Prescott characteristically points out that in the process [of learning to understand how the body works] you learn quite a lot about how the mind works' (Maimaris 2006: 29).

According to a phenomenological perspective, therefore, the body-mind unity that yoga is expected to achieve is understood in terms of the practitioner's mental and emotional landscape. In phenomenological terms, the practice of yoga confirms and accentuates an approach towards the body as the 'locus of experience'. It thus is understood as inextricably connected to the practitioner's proprioceptive, cognitive, emotional and behavioural attitudes. As such, according to philosopher Yasuo Yuasa, body-mind unity can be regarded as an 'achievement', a 'state actualized by exemplary individuals' (Yuasa 1987: 1) and not simply as a constant and universal connection which either is or is not there. The integration of body and mind is therefore a possibility that can be rendered present through training. Through cultivation, Yuasa argues, the body may lose its heaviness, overcome its inertness, and cease to object to the mind (1987: 69). The mind, on the other hand, may overcome the tendency of being a subject opposed to objects, it may give up ego-consciousness and in Yuasa's words 'enter a state of self-less samadhi or what may be called a self without self' (Yuasa 1987: 69). Based on such an understanding of body and mind, spirituality could be viewed as the very realisation of this radical experience of their unity. Spirit is no longer regarded as separate and superior to the flesh, but a continuation, an entailment of psychophysical integration. Spirituality is, therefore, a state in which the barriers between object and subject are lifted and limited individual consciousness is transcended. 


\section{Yoga as a social practice}

Whereas a phenomenological exploration of yoga seems to affirm the claims that its practice can unify body and mind and indeed lead to spiritual attainment, an examination of the discipline through the lens of cultural materialism paints a very different picture. According to such an approach, yoga is viewed not only as a practice that takes place in a particular time and place, but rather as a result of such time and place. Such a perspective would reveal that certain principles that underlie the practice and pedagogy of yoga postures are inextricably connected to notions that were developed and popularised from the eighteenth century onwards. An upright posture, an aligned skeleton, and an economical sense of movement underpin the teaching of most MPY regimes and in some cases these traits are being upheld as ideals, which the practitioner tries to emulate. These principles appear to be sensible prerequisites for a healthy and balanced body, and indeed according to Yuasa, certain Japanese forms of spiritual cultivation regard the attainment of a correct physical position as an essential premise for spiritual development (1984: 100). However, when these principles are viewed from a historical perspective and in relation to Western culture, it becomes clear that they became prominent at a particular point in time and have in fact both social and political connotations.

In an article that traces the 'upward training of the body' from the Middle Ages to the emergence of court societies, Georges Vigarello points out that the cultivation of upright posture-by means that have historically variedhas been connected to the acquisition or maintenance of social ranking. As a result, from the Middle Ages onwards, the body becomes 'heavily laden with demonstrative value', since 'one's breeding is evident in one's physical training' (Vigarello 1989: 156). In a similar vein, Joseph Roach argues that accepted modes of behaviour, manners and comportment have always been part of wider ideological strategies that aim to impose a clear distinction between social classes as well as promote the interests of the upper ones. Roach points out the way eighteenth- and nineteenth-century techniques of training, such as 'military formations, conduct books, even handwriting exercises' aimed at the 'internalization of social discipline' and the maintenance of the political, social and economic status quo (Roach 1989: 159). Similarly, with regard to late capitalist societies, Bryan Turner observes that the body has become an 'indicator of cultural capital', whereas the maintenance or production of youthfulness, fitness and beauty has been met by a significant degree of personal and financial investment (Turner 1996: 3). The emphasis placed on the 
body in contemporary culture is thus related to what sociologists term 'the self project', 'within which individuals express their own personal emotional needs through constructing their own bodies' (Turner 1996: 5). The body, therefore, is seen as 'a changeable form of existence which can be shaped and which is malleable to individual needs and desires' (Turner 1996: 5).

In view of the aforementioned currents and developments, one could situate the popularity of yoga, and indeed the widespread practice of MPY, within this wider nexus whereby the body is moulded, regulated and governed according to, and in order to promote, specific values and aims. In modern configurations yoga has acquired an explicit health and fitness orientation, whereas practices of yoga today fall under the sport and leisure domain. At the same time, yoga has been cast as a form of physical/spiritual/holistic therapy, advocated both by mainstream doctors as well as practitioners of alternative medicine. In an article that examines the disciplinary nature of alternative therapies, the cultural theorist Ruth Barcan employs Michel Foucault's argument and claims that 'the vigilance of external bodies is supplemented to a greater or lesser degree by self-monitoring, self-"management", self-surveillance' (Barcan 2008: 15, emphasis in original). Alternative therapies, and among these Barcan explicitly includes yoga, can thus be seen as manifestations of internalised forms of self-government. Contrary to popular beliefs, therefore, it could be argued that the practice of MPY, while supposedly ridding the body of the tensions and toxins of urban environments, at the same time renders the body productive, efficient and docile. According to this view, yoga not only fails to liberate the practitioner, but subjects one further to the disciplinary power of social and political mechanisms. De Michelis's observation that yoga is practised in total autonomy from institutional and societal control' (2004: 211) acquires an ironic twist, since practice of yoga comprises a distinct form of self-regulation and body management and as such it can be construed as a practice that supports hegemonic structures. The practice of MPY could therefore be seen as one more example in a long series of techniques which aim to regulate the body, so that discipline is internalised and the social status quo is maintained.

The disciplinary and regulatory function that can be attributed to MPY practices can be further identified in the way the asanas are being taught. The importance of orthoperformance as well as attention to skeletal alignment is potentially the way in which the practice calms the mind and fosters a meditative state. On the other hand, it could be argued that these pedagogical principles, apart from cultivating an upright posture which, as we have seen, is fraught with political and social implications, also lead to the objectifica- 
tion of the body. During a yoga class, the body is subject to a process of assessment, measurement and analysis according to 'scientific principles' and 'anatomical rules'. It is placed under the objectifying gaze of the teacher, who instructs, incites and corrects the body through verbal instruction, tactile adjustment, and physical demonstration. The practitioner's body is thus constantly compared to the ideal shape of the asanas, as the latter are exhibited by the teacher, photographs of the creator of a specific approach, or the student who performs the pose 'correctly'. Such a process turns the individual lived body, the soma of the practitioner, into a material object which strives to achieve predetermined shapes.

The aforementioned pedagogical approach becomes further evident in the language often employed in MPY contexts. As the practice of postures has become more sophisticated, the verbal instructions that accompany the teaching of the postures feature a distinct vocabulary, which is drawn from anatomy and physiology and tends to become more detailed and intrinsic as the student progresses. Body parts are broken down to minute detail, muscles are precisely named and bodily movements are described in an analytical fashion. In this manner, MPY draws extensively on a Western scientific paradigm, which is underpinned by body-mind dualism and views the body as a machine that can be regulated by the mind. ${ }^{6}$ At the base of MPY pedagogy we thus find the following paradox: while the practice of the asanas is expected to unite body and mind, their teaching is often characterised by a mechanistic and instrumentalist approach, which views the body as something malleable that can be changed and subordinated, if sufficient effort and control is exerted. It could be argued therefore that not only the social context, but also the pedagogy that underlies MPY practices have at the centre a body that resembles Descartes' 'corpse' rather than Merleau-Ponty's 'lived body'. As a result, although MPY placed the body at the centre of its praxis, it is still burdened by pedagogical, scientific and ideological models that institute a clear distinction between body and mind, whereby the body is the instrument of action and the mind the site of the intellect, control and decision-making. to be validated as an alternative form of therapy for a number of ailments, which are nonetheless determined and classified according to Western medicine, its practices have been assessed according to Western biomedical methods. However, 'the process of validation through Western science often means (as an unintended consequence) the application of a paradigm underpinned by dualistic notions of an essential relationship between the mind-body' (Brown \& Leledaki 2010: 137). 
An examination of yoga through cultural materialism brings to the foreground, therefore, that the body-mind unity which MPY aims or claims to engender is subject to a number of factors, which might prohibit such an endeavour. This, of course, does not discredit the understanding of individual teachers and practitioners who may experience the integration of body and mind in the manner, for example, that a phenomenological analysis frames such a possibility. However, what a cultural materialist perspective makes clear is that MPY cannot be viewed or indeed practised independently of certain socio-economic contexts and completely free of pedagogical paradigms that view the body as a mere instrument. From this point of view, MPY acquires a disciplinary character, which also forecloses the very possibility of spiritual development. In fact, one could further argue that the promise of spiritual attainment is nothing more than an excuse for the disciplinary power of the training. Instead of asking whether asanas have a spiritual dimension that redeems them from being mere gymnastics, one might as well ask what is the social function of such premise. Why is MPY presented as a form of spiritual pursuit? Why do the practitioners need to invest the practice with a spiritual dimension? Could spirituality serve as an excuse for the propagation of a practice that keeps Western populations physically and mentally healthy, productive, docile?

\section{Conclusion}

The two approaches employed in this paper have foregrounded different aspects of MPY. As I have already mentioned, my feeling is that these aspects, albeit contradictory with each other, are both contained within the ideology and practice of the discipline. It would also seem to me that, although both these approaches foreground important aspects of the practice, they do not encompass it in its totality. The phenomenological approach renders yoga ahistorical and ostensibly concentrates on the individual and her experience. The cultural materialist viewpoint cannot account for the ways in which yoga can act as a technique for empowerment and spiritual cultivation. More importantly, both currents seem to exist as possibilities within the same class, even within the same body. The practice of a single asana can bring body and mind closer and thus open possibilities for mental, emotional and spiritual development. The very same practice may develop an instrumentalist attitude towards the body, and thus cause a further dislocation between body, mind and spirit. As a result, the claim that MPY unites body and mind and is a 
form of spiritual practice needs to remain provisional and contingent. For this reason, it is important to look at specific instances of yoga practice/tuition and pay attention to the pedagogical tools and principles employed. More importantly, a theoretical framework needs to be developed that could take into account both the various ideologies within/according to which yoga currently operates, as well as the personal psychophysical experiences that practitioners may have. Finally, the number of discourses, psychophysical possibilities, and metaphysical expectations that operate not only within the space of MPY practice, but in a number of similar disciplines, point towards a need to reconfigure these terms that MPY loves to employ but hates to define. What are body, mind and spirit and can the peculiar blend of MPY serve as a basis to redefine these terms?

\title{
Bibliography
}

\author{
Alter, Joseph \\ 2008 'Performativity and the study of yoga.' In: Mark Singleton \& Jean Byrne \\ (eds), Yoga in the Modern World: Contemporary Perspectives. 36-49. Oxon: \\ Routledge. \\ Barcan, Ruth \\ 2008 'Alternative therapies as disciplinary practices: the uses and limitations of \\ a Foucauldian approach.' In: Nicole Anderson \& Katrina Schlunke (eds), \\ Cultural Theory in Everyday Practice. 14-27. South Melbourne: Oxford UP.

\section{Brown, David \& Aspasia Leledaki} \\ 2010 'Eastern movement forms as body-self transforming cultural practices in the \\ West: towards a sociological perspective.' Cultural Sociology 4 (1): 123-54.

\section{Deutsch, Eliot} \\ 1993 'The concept of the body' In: Thomas Kasulis, P. Ames, T. Roger \& Wimal \\ Dissanayake (eds), The Self as Body in Asian Theory and Practice. 5-20. \\ Albany: State University of New York Press.

\section{Grosz, Elizabeth} \\ 1994 Volatile Bodies. Bloomington and Indianapolis: Indiana University Press.

\section{Heelas, Paul} \\ 2008 Spiritualities of Life. Oxford: Blackwell Publishing.

\section{Leder, Drew} \\ 1990 The Absent Body. Chicago: The University of Chicago Press.

\section{Maimaris, Diane} \\ 2006 'A conversation with Silvia Prescott.' Iyengar Yoga News 9: 26-9. \\ Michelis, Elizabeth De \\ 2004 A History of Modern Yoga. New York: Continuum.
}


Murray, Simon \& John Keefe

2007 Physical Theatres. London: Routledge.

Nevrin, Klas

2008 'Empowerment and using the body in Modern Postural Yoga'. In: Mark Singleton \& Jean Byrne (eds), Yoga the Modern World: Contemporary Perspectives. 119-39. Oxon: Routledge.

Roach, Joseph

1989 'Theatre, history and the ideology of the aesthetic.' Theatre Journal 41 (2): 155-68.

Shilling, Chris

1991 'Educating the body and the production of social inequalities.' Sociology 25 (4): 653-72.

\section{Turner, Bryan S.}

1996 The Body and Society: Explorations in Social Theory. London: Sage Publications.

\section{Vigarello, Georges}

1989 'The upward training of the body from the Age of Chivalry to courtly civility'. In: Michael Feher, Ramona Naddafi \& Nadia Tazi (eds), Fragments for a History of the Human Body. 148-99. New York: Zone.

\section{Williams, Simon \& Gillian Bendelow}

1998 The Lived Body. London: Routledge.

Yuasa, Yasuo

1987 The Body: Towards an Eastern Mind-Body Theory. Albany: State University of New York Press. 